\title{
Converting Dam: from Water Supply to Hydropower Generation
}

\author{
Heng Hock Hwee, Associate Director, SMHB Sdn Bhd \\ Hii Ching Poon, Independent Consultant
}

Siaw Fei Lu, Senior Lecturer, Faculty of Engineering and the Built Environment, SEGi University

Pan Wang Fook, Senior Lecturer, Faculty of Engineering and the Built Environment, SEGi University

\begin{abstract}
This study investigates the feasibility of converting four (4) existing single purpose water supply reservoir schemes into conjunctive hydropower operation that could supply raw waters to respective water treatment plants and at the same time, generate power. These dams with proper retrofitting exercises could be a potential hydropower cum direct water supply reservoir operation. The change in operation does not only berth well with current trend of dual or multipurpose functions of the reservoir scheme but also in light of emerging role of hydropower as a mature and steady source of renewable energy. These dams were assessed for retrofitting with turbine to generate hydroelectricity and at the same time, to supply raw water to both water supply schemes. Despite the advantages of this dual function of the existing reservoirs schemes, this study however concludes infeasible tasks as only less than $1 \mathrm{MW}$ of firm power can be harnessed. To reconfigure these existing infrastructures for purpose other than for the single purpose of water supply requires optimum storage capacity and hydraulic head, the two most important variables, in essence, especially for viable hydropower generation. In addition, the height of the dam dictates critically the magnitude of effective head but unfortunately unavailable readily for most of the existing dams evaluated in this Study. They are less than $60 \mathrm{~m}$ in height in general. The design philosophy for the reservoir schemes at their preliminary conceptualization also does not support future multipurpose components of the reservoir operation. However a positive development of these potential schemes could be beneficial to
\end{abstract}


supply power to the local community in the surrounding areas in additional to plant consumption

\subsection{Introduction}

Hydropower is generated by converting kinetic energy in flowing water into electrical energy. The water flows via a channel or penstock and strikes a waterwheel or turbine, causing the shaft of the turbine to rotate. To generate electricity, the rotating shaft which is connected to an alternator or a generator, converts the mechanical energy of the shaft into electrical energy. It is a rather mature and time-honored conventional power generation technology accounting for a substantial portion of the total energy production worldwide, at about 20\% of the global energy output (Mays, 2011; Mishra et al., 2015).

Some $50 \%$ of the total renewable sources output are contributed by the hydropower scheme worldwide (Carraso, 2011). Hydroelectricity is clean, and can be a substitute for non-renewable sources (e.g., oil, coal and natural gas) in the production of electricity. Hence, the generation of electricity does not result in the emission of greenhouse gases (Chen et al., 2016). In terms of geographical distribution, Countries such as China, Russia, Brazil, Norway, USA, India, and Canada account for major hydropower production percentage with their large land coverage and endowed water resources. In Malaysia, the total installed capacity in the Peninsula stood at 20,710 MW whereby $10.38 \%(2149 \mathrm{MW})$ is from hydroelectric (Suruhanjaya Tenaga, 2016).

The hydropower schemes installed in stream to the river divert waters as in the case of run-of-river operation to the power house which is located mostly further downstream. This is essentially to create higher elevation difference. In another category of hydropower scheme with storage facility, the power is generated by the energy storage that taps into the effective head or water elevation, the water flow rate. In both cases, under suitable condition the water power turns the turbine to drive a power generator. A modern turbine system could have as higher as $90 \%$ of overall efficiency. 
Nevertheless, as compared to large-dam hydropower projects, smallscale hydroelectricity is a more sustainable alternative as a clean, green, and socially just power generation technology. Especially in emerging economies, the environmental, social, economic, and technical sustainability of large-scale hydropower has been severely criticized (Manders et al.,2016). A small scale hydroelectric facility should be designed with a sizable flow of water and a proper water elevation, without building elaborate and expensive facilities.

Water is basically conserved in the sense that it is not normally consumed by the hydropower installation. It is a non-consumptive utilization when water is released downstream via networks of pipelines to the intended water treatment plants. Another advantage of this direct supply route to the power house and water treatment plant is that a much better raw water quality can be obtained from the reservoir. Along the way, there is barely any opportunity for cross contamination as in the case of when the reservoir water is released via the natural river channel from the dam site to the receptors (water intakes) downstream. Therefore, it can be used for other purposes as well. Examples are such as cogenerating hydropower that might be suitable for at least satisfaction of the on-site power needs.

\subsection{Objectives and Aims}

This study endeavors to investigate the feasibility of converting the existing water supply reservoir/dam schemes into dual water supply and hydropower operations. Four (4) existing dams were targeted for assessment if the conversion from water supply to hydropower function can be feasible. The location of these existing reservoir schemes are shown in Figure 1. 


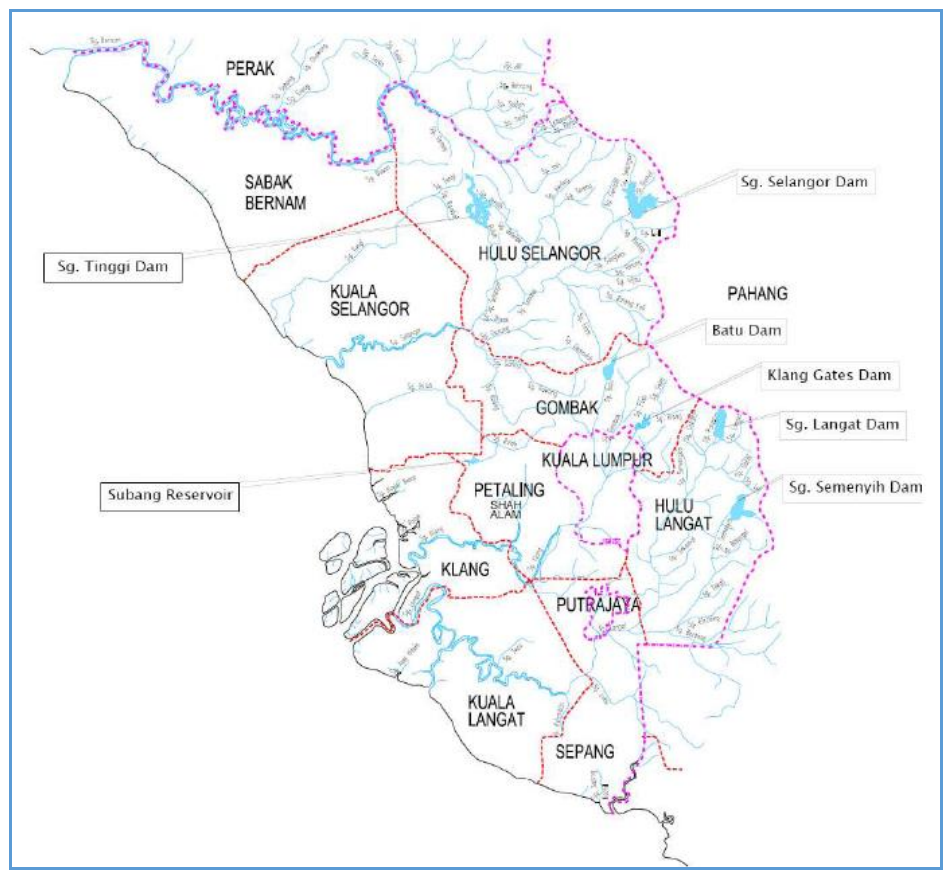

Figure 1: Dam Locations in the State of Selangor and Kuala Lumpur

For both Langat and Semenyih dam, one of the reasons for this potential change of water supply operation mode from the existing regulating type of water supply scheme is due to the fact of excess waters with the commissioning of an on-going a single large scale interbasin raw water transfer. The newly available raw water sources assessed base on a $98 \%$ reliability criterion can supply up to 1900 Mld, which doubles the total capacity of the existing reservoir schemes of about 1090 Mld. This might create a situation of overcapacity of the current and future water demand supply dynamics.

This excess of capacity further renders redundancy to the overall water supply schemes in the State of Selangor as well as Kuala Lumpur. It is therefore of the interest to investigate viable options in utilizing excess waters of the existing Langat and Semenyih reservoir schemes for other beneficial uses. 
On the other hand, both Klang Gates and Batu dams that are located at the upper catchment of Klang River basin are of direct supply reservoir operation where the waters are directly supplied to the respective water treatment plants. The direct supply operation of the reservoir is most conducive to potential hydropower development as for the case of Klang Gates reservoir scheme, the water is piped by two- $1.2 \mathrm{~m}$ diameter penstock to the water treatment facility.

Amongst several options considered, this study only focuses on hydropower generation potentials of these dams after suitable retrofitting exercise. It is important to note that the conversion of the water supply reservoir into sole hydropower generating or dual hydropower and water supply operation seems promising. In addition, the hydropower is a renewable energy that generates electricity by the running waters and advantages of higher water elevation.

\subsection{Literature Review}

There are not many literature on the conversion and retrofitting of dam to other beneficial uses that were not intended or designed for. This makes a systematic literature review undertaking difficult to be accomplished. Kucukali (2010) carried out a study to locate the most convenient location in the water supply systems for power generation. The location identified was most conveniently located along the water supply penstock lines before entering into the water treatment plant and/or distribution network. Hydropower generation could be possible at these two strategic locations.

Mol et al. (2011) presented an inventory of the possibilities to recover sustainable energy from the water cycle by taking advantage of different water flows in a municipal/domestic water supply sector. It also discussed the role that public water utilities should play in the market of harnessing energy from water flow. Furthermore, a demonstration was accomplished in Waternet, the public water utility of Amsterdam, by describing experiences of two practical applications for aquifer thermal energy storage and energy recovery from drinking water. It was also concluded that public water utilities can substantially contribute to the production of sustainable energy, 
especially by making use of differentials in temperature distribution from the water cycle.

One of the bigger challenges of the dual operation of domestic water supply ad hydropower generation is the design return period to be selected a priori. For water supply project, the reliable yield, continuous supply of raw waters to the water treatment facility for a given probability of occurrence is estimated based on a $98 \%$ reliability criteria. This is commonly known as a 1:50-year return period. In Malaysia, this definition was chosen as the primary water supply reservoir scheme design based on Twort's definition and methodology (Johnson et al., 2009).

With population projections indicating continued growth, improved dam design is important in order to meet both future water and energy demands. Dams should be designed to be multi-purpose, including the generation of hydropower. In fact, The World Bank notes that hydropower dams have a role in the management of water resources, including water allocation as well as management of floods and droughts (Chen et al., 2016)

\subsection{Existing Regulating Reservoir Operation}

Both existing Semenyih and Langat schemes supply a total of 1091 Mld (637 and 454 Mld for Semenyih and Langat schemes respectively) of treated waters to various demand centers in Kuala Lumpur and its vicinity. Both schemes are being operated originally based on the regulating reservoir mode as in the earlier engineering design without considering multipurpose components at that time, whereby reservoirs are only releasing waters intermittently upon shortfall/deficit at the respective intakes.

During the operation of the reservoir scheme, the amount of water deficit was estimated by the operator at the treatment plant a priori about one-day ahead of time. The request is then made accordingly to the dam operators on the timing and magnitude of releases other than the compensation mandatory by law and eco-environmental requirement. The releases of reservoir waters were to be commenced earlier (about 14 to 18 hour ahead) depending on the flow rate as it 
would take time to meander through the mountainous hinterland of the river basin to reach the respective intakes on time. On the other hand, during such time of higher flow regime at the intakes especially during the annual monsoonal seasons, the reservoirs are therefore only releasing compensation flows for environmental sweet water maintenance.

During this intermittent period, unless major spills happen, power generation capability will be lower only to take into the compensation flow rate as its primary variable. This presents a conflict of dual water supply and hydropower generation endeavors and utilizations as most of the reservoir operation rules are only designed to prioritize water supply operation. For hydropower generation, a larger constant release is a prerequisite to enable steady power generation and in addition, to maintain higher elevation at the respective reservoirs.

\subsection{Semenyih And Langat Water Supply Schemes}

The Langat reservoir is located at the upper forested catchment on the main stem of Langat river basin. The reservoir drains a smaller catchment area of $41 \mathrm{~km}^{2}$ at the western slope of the headwaters of the central mountain range. The intake drains a total area of $295 \mathrm{~km}^{2}$. The corresponding gross storage is $35.4 \mathrm{MCM}$ with about $1.3 \mathrm{MCM}$ is designated as the dead storage. The existing Langat scheme water treatment scheme can produce about 454 Mld of a 1:50-year return period reliable net yield with $90 \mathrm{Mld}$ and 9 Mld compensation flows at both the intake and dam sites respectively. The FSL is at $+221 \mathrm{~m}$ $\mathrm{msl}$ at the rim of a morning glory spillway. The dam height is about $61 \mathrm{~m}$ from its foundation.

The Semenyih reservoir is located on one of the major tributaries, Semenyih river on the northeastern region of the Langat river basin. The catchment area at the dam site is $57 \mathrm{~km}^{2}$ where the existing water intake is located further downstream near the confluence of Langat and Semenyih rivers. The intake drains a much larger catchment area of about $571 \mathrm{~km}^{2}$. Gross storage of the reservoir is about $62.6 \mathrm{MCM}$, out of this, 2.2 MCM is allocated for dead or sediment storage. The water supply scheme can produce 636 Mld in capacity with some 20 
Mld and 115 Mld compensation releases at the dam and intake sites respectively. The $49 \mathrm{~m}$ high earthfill embankment dam is located in a lower elevation, with $+111 \mathrm{~m} \mathrm{msl}$ as FSL. Similar to Langat dam, Semenyih dam is also equipped with similar type of spillway structure.

\subsubsection{Klang Gates And Batum Dam Scheme}

The Klang Gates reservoir was originally built for flood mitigation purpose at the upper catchment of Klang River in the 1950's. The function was further expanded to water supply scheme in the mid 1960's after a major upgrading work. The reservoir of its capacity of about $28 \mathrm{MCM}$ at its nominal pool level of $+95.2 \mathrm{~m}$, is considered as an "annual" storage reservoir where on average year basis, the dam would be full after the monsoonal season. Based on $1000 \mathrm{~mm} /$ year of annual average flow at the dam site $\left(C A=77 \mathrm{~km}^{2}\right)$, the equivalent runoff is about $77 \mathrm{MCM} /$ year. The raw water is piped by gravity to the 136 Mld capacity water treatment plant about $6 \mathrm{~km}$ southward.

The Batu dam was built in the 1990's as part of the flood mitigation plan for the city of Kuala Lumpur. The water supply component of the original design is an add-on to the main objective. The dam of about $50 \mathrm{~km}^{2}$ in catchment area is located on a major tributary of Klang river. The dam serves both flood mitigation and domestic water supply at the western peri urban area of Kuala Lumpur, to only a certain limited extent scenic and recreational values and outlets for the city dwelling folks. The dam is about $33 \mathrm{MCM}$ in capacity at nominal pool level of $+103.0 \mathrm{~m}$. The raw waters are released via bottom outlet and are diverted into the water treatment plant a short distance downstream of the dam site. The design capacity of the treatment is 115 Mld. This was believed to be the reliable yield assessed earlier.

\subsection{Potential Direct Supply Reservoir Cum Hydropower}

\section{Operation}

The proposed direct water supply mode of operation, as its name implied, supplies waters directly to the water treatment plants via 
pipeline or in a rare occasion by releasing through the river channel, which acts as a conveyance to the intake at further downstream.

This mode of operation by directly piping water to the treatment plant normally ensures a better water quality vis-à-vis a regulating reservoir mode. But this is at the expense of rather expensive pipeline and other accessories such as valves etc. Pumping is also normally not required as wasters can gravitate from higher to lower elevation at the treatment plant.

In a way, the waters that are piped directly to the respective water treatments could be harnessed for hydropower generation by taking advantage of both the flow rate and the elevation head. In addition, he waters released en route to the treatment plants along the way, are renewable in the power production.

\subsubsection{Calculation Approach}

The schemes operate on a direct supply mode of operation where the waters stored behind the reservoir are released to the penstock through the bottom outlet in tandem with the compensation flow. For the normal hydropower operation, the water level is to be kept higher almost at the FSL level as much as possible so that to increase their hydraulic heads. But this cannot be assured at best if the reservoir persists on drawing down to meet the domestic water demand of the respective water treatment facilities downstream.

In such a case, the water storage could therefore be withdrawn down to some depths before reaching the minimal operating level (MOL) and still be able to produce electricity. Only when the reservoir is about to draw to its dead storage level, then the hydropower generation operation ceases to operate from this time onward until the reservoir begins its refilling phase during high flow hydrological regime.

During a high flow episode, the waters may also overflow the morning glory spillways for both Langat and Semenyih dams but for Klang Gates and Batu dams, gated spillway and ogee chute channel respectively. These opportune flows are considered in the power estimation to produce power duration curve as they are parts of the 45 
quantum of flow provision for power generation. In addition, the other flows such as for satisfying the domestic water demand, reliable yield and environmental requirement are then released constantly from the reservoir.

At the downstream of the dam, the flow will be channelled to the proposed hydropower turbine for power generation. The water balance calculation at the reservoir includes the input terms, such as inflows and on the other hand, the outflow terms are the lake evaporation and the amount of water that has to be channel to the intake tunnels, including the compensation flow.

The power is calculated based on two pertinent independent variables (1) flow discharge and (2) elevation head from the full supply level (FSL) to the bottom outlet or tailwater race. It is also assumed that the specific weight of water is $9810 \mathrm{~kg} / \mathrm{m}^{3}$. In this Study, the overall efficiency of the hydropower scheme is assumed 0.90. A constant head loss, about 5 to $10 \%$ of the differential elevation head is also assumed to represent all head losses due to frictions in the penstock, valves, and other minor losses in bends, contraction, and expansion along the pipeline/penstock system as well.

The scenario run is based on monthly time step interval gives the remaining active or live storage volume at the end of the month. The corresponding elevation and the storage can then be estimated from regression equations fitted through the storage-elevation data of the respective reservoir.

\subsection{Results And Discussion}

\subsection{Semenyih Dam Scheme}

The proposed hydropower scheme was based on long-term 60-year monthly hydrological records (1950-2009) at the Semenyih dam site. The constant release was made solely for water supply purpose. Notwithstanding the ultimate commission of Interstate water supply from a neighboring catchment with a bulk capacity of 1900 Mld. About $20 \%$ of the reliable yield, 128 Mld out of the original Semenyih regulating reservoir scheme capacity of 636 Mld could also be 
harnessed in tandem with the proposed hydropower development. This cutback could have been possible once the excess capacity of a much larger scheme is to be commissioned.

Figure 2 shows the drawdown curve of the Semenyih dam based on a 1:50-year reliable net yield of $128 \mathrm{Mld}\left(1.50 \mathrm{~m}^{3} / \mathrm{s}\right)$ constant release downstream. On the concurrent hydropower generation, the estimated power capacity at $50 \%$ exceedance was only about $0.48 \mathrm{MW}$. This was estimated based on utilization of flow releases, i.e. targeted releases to the downstream WTP, compensation releases for environmental maintenance of the riparian river, and occasional spillages from the reservoir. The annual power generation on average was estimated by integrating the area under the power duration curve, i.e. about $4.83 \mathrm{GWh}$.

The generation of hydropower could be further increased if the elevation differential was much greater, i.e. from the full water level at the reservoir surface to the center line of turbine machinery in the power house. The most favorable choice to create higher head should logically be located further immediately downstream of the dam site on a suitable site near or before the water treatment plant. Figure 3 shows the power or load duration curve of the Semenyih reservoir scheme. The powers in megawatt (MW) for various probabilities of occurrence, i.e. from 50 to $98 \%$ exceedance and annual power output are tabulated in Table 1.

\subsection{Langat Dam Scheme}

The proposed hydropower scheme is based on long-term about 64year hydrological records (1950-2013) at Langat dam site. Similarly to Semenyih dam presented in the earlier discussion, this was amounting to approximately one-fifth of the regulating reservoir yield of the existing operating Langat reservoir scheme. Figure 4 shows the drawdown curve of Langat dam/reservoir based on a 1:50-year reliable net yield of $90 \mathrm{Mld}\left(1.04 \mathrm{~m}^{3} / \mathrm{s}\right)$ constant release downstream. The constant release of water was intended for domestic water supply purpose as opposed to intermittent release to augment the flow deficit at the downstream intake $\left(\mathrm{CA}=295 \mathrm{~km}^{2}\right)$. The $50 \%$ exceedance 
capacity is about $0.34 \mathrm{MW}$. This is comparatively smaller than the Semenyih scheme. The annual power generation is about $4.83 \mathrm{GWh}$.

According to the power derivation equation, increase in the magnitude of hydraulic head relatively considered achievable as there was always a limitation in the water resource. The logical choice was immediately downstream of the dam site and a second location was at a further distance downstream location near the existing Langat water treatment plant. Figure 5 shows the power duration curve of Langat dam scheme.

The firm powers in megawatt (MW) for various probabilities of occurrence, i.e. from 50 to $95 \%$ exceedance are tabulated in Table 1.

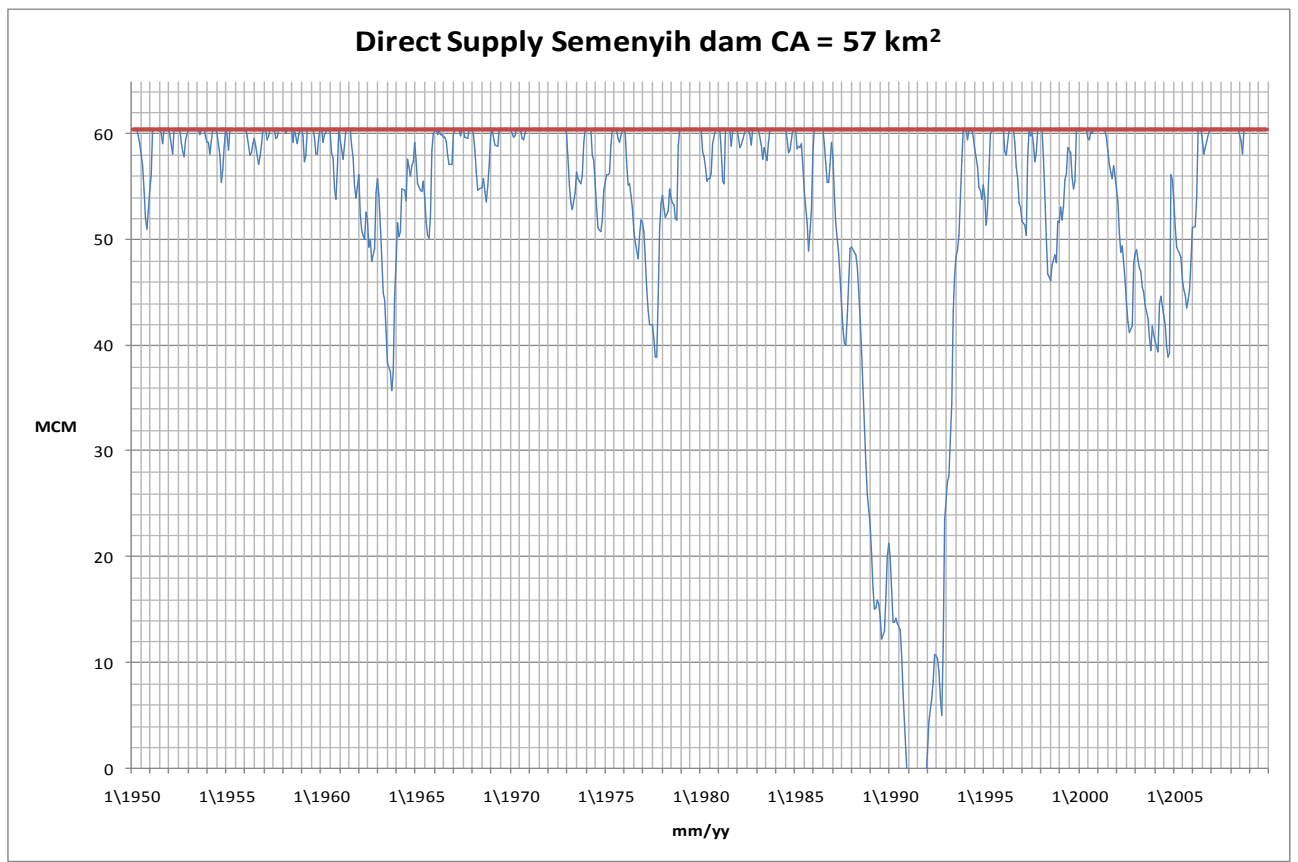

Figure 2: Drawdown Curve for Semenyih Reservoir 


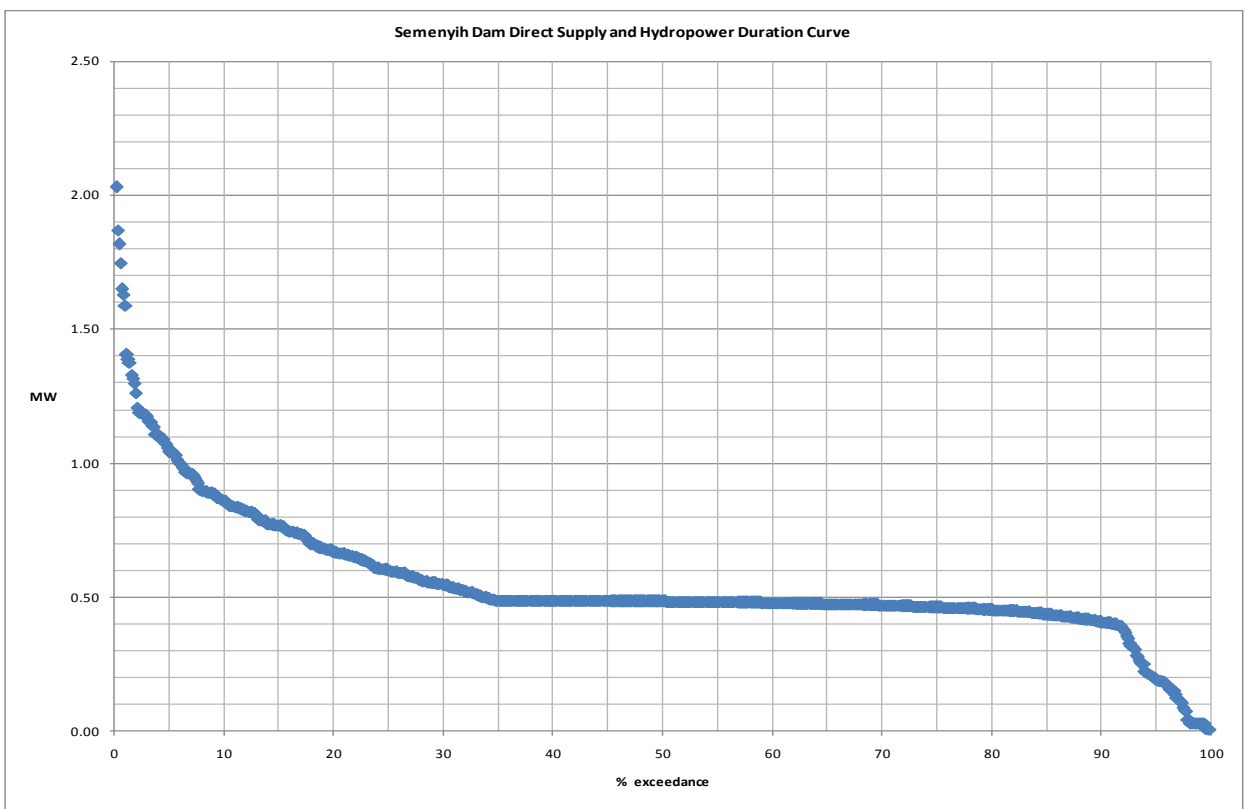

Figure 3: Semenyih Dam: Power Duration Curves

\begin{tabular}{|l|l|l|l|l|}
\hline & $\begin{array}{l}\text { Semenyih } \\
\text { dam }\end{array}$ & Langat dam & $\begin{array}{l}\text { Klang Gates } \\
\text { dam }\end{array}$ & Batu dam \\
\hline $\begin{array}{l}\text { Catchment area } \\
\mathrm{km}^{2}\end{array}$ & 57 & 41 & 77 & 50 \\
\hline & $+\mathbf{m}$ msl & $+\mathbf{m}$ msl & $+\mathbf{m}$ msl & $+\mathbf{m}$ msl \\
\hline NOL +m msl & +111.0 & +221.0 & +95.2 & +103.0 \\
\hline TWL +m msl & +79.0 & +183.0 & +60.0 & +84.0 \\
\hline$\%$ & KW & KW & KW & KW \\
\hline 50 & 0.48 & 0.34 & 0.53 & 0.22 \\
\hline 80 & 0.45 & 0.33 & 0.41 & 0.22 \\
\hline 90 & 0.41 & 0.24 & 0.39 & 0.22 \\
\hline 95 & 0.19 & 0.21 & 0.35 & 0.22 \\
\hline & GWh/year & GWh/year & GWh/year & GWh/year \\
\hline Energy output & 4.83 & 3.36 & 5.69 & 2.49 \\
\hline & Mld & Mld & Mld & Mld \\
\hline $\begin{array}{l}\text { WTP capacity } \\
\text { Mld }\end{array}$ & 636 & 454 & 145 & 114 \\
\hline Current study & 128 & 90 & 128 & 127 \\
\hline
\end{tabular}

Table 1: Power Capacity of Various Dams 


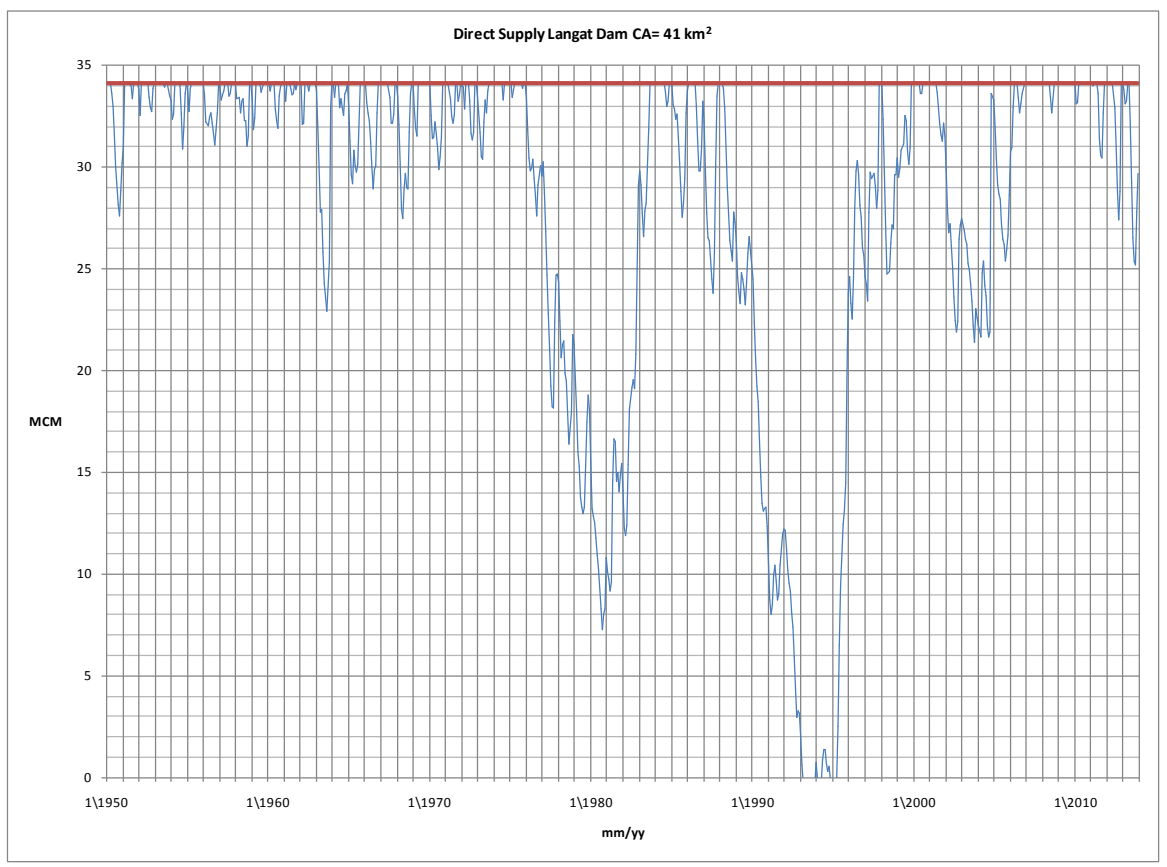

Figure 4: Drawdown Curve for Langat Reservoir

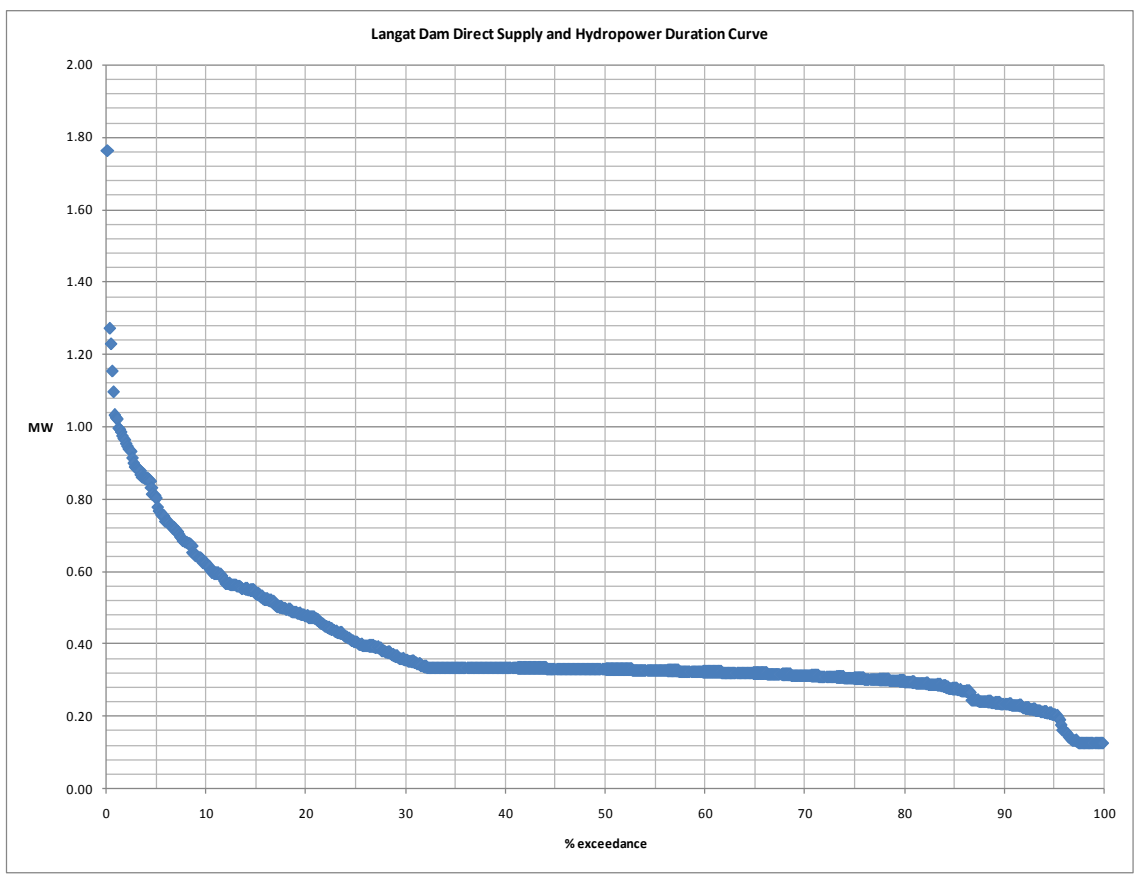

Figure 5: Langat Dam: Power Duration Curve 


\subsection{Klang Gates Dam Schemes}

The Klang Gates dam is a dual function, i.e. water supply and flood mitigation purposes. To incorporate hydropower component in the design only requires the water level to be located at $+95.2 \mathrm{~m} \mathrm{msl}$, nominal pool level or about $28 \mathrm{MCM}$. An extra storage of about 3 MCM above the nominal pool level with the raising of the dam by 1.5 $\mathrm{m}$. These storage is considered unavailable for both domestic water supply and power generation alike.

The power that can be generated based on 50\% probability of exceedance was about $0.53 \mathrm{MW}$ (see Table 1). This was about the highest power capacity amongst the four dams undertaken in this Study. In terms of energy out, about $5.68 \mathrm{GWh}$ can be generated on yearly basis, on average. Similarly this was the highest output of all the other dam schemes. Figures 6 and 7 shows the reservoir drawdown curve and power duration curves of Klang Gates dam respectively.

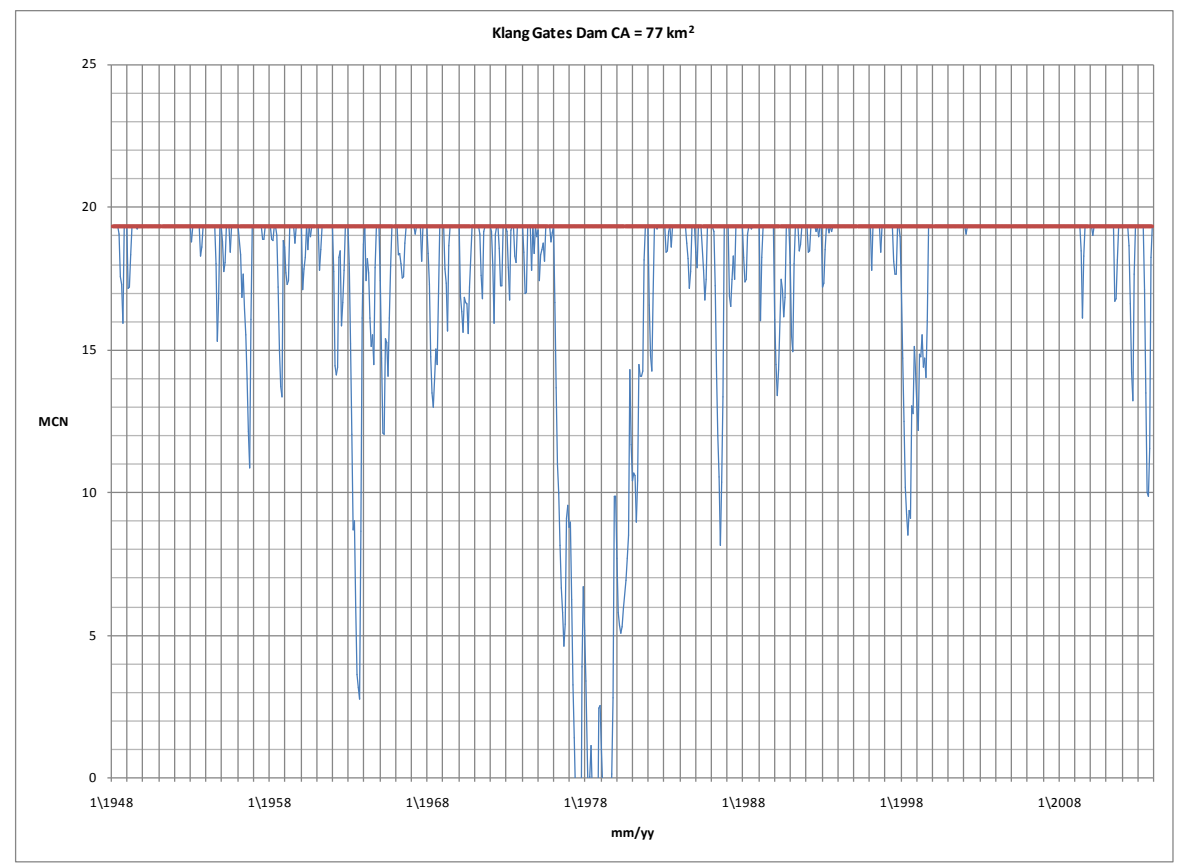

Figure 6: Drawdown Curve for Klang Gates Reservoir 


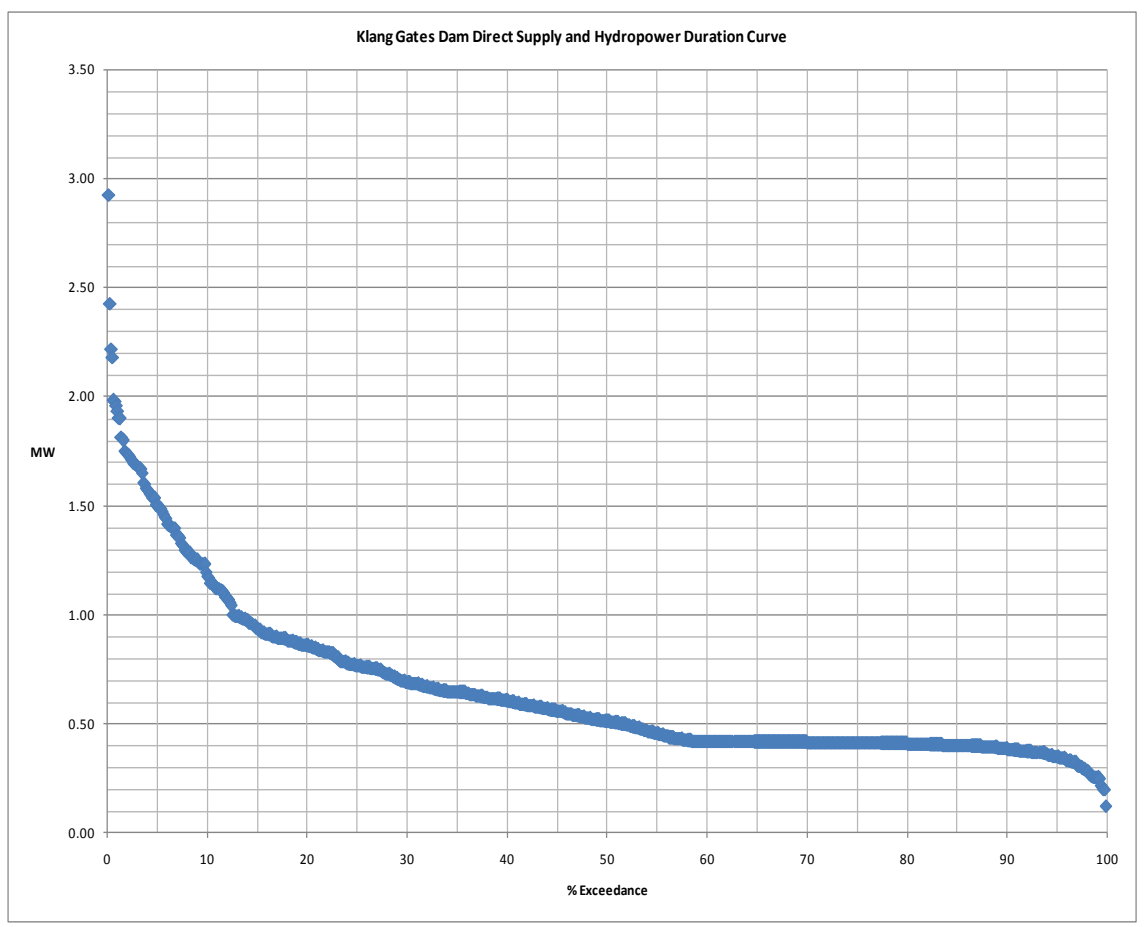

Figure 7: Klang Gates Dam: Power Duration Curve

\subsection{Batu Dam Scheme}

Sixty six (66) years of monthly inflow records were utilized in the direct supply reservoir operation run. The reliable yield of a 1:50year return period was about 127 Mld slightly higher than the nominal capacity of the water treatment plant. The power duration curve shows a much uniform power capacity for exceedance of more than $50 \%$ to $95 \%$ at about $0.22 \mathrm{MW}$. This situation shows that the output is at its minimum with only the minimum flow of about $1.5 \mathrm{~m}^{3} / \mathrm{s}$ to be released for power generation. The energy output is approximately $2.5 \mathrm{GWh}$ per annum on average. This was the lowest compared to three other dam scheme primary due to its available head. The flow rate did not play a major role in hydropower generation because the reliable yield that could be harnessed is about the same vis-à-vis other dam schemes.

Figures 8 and 9 shows the reservoir drawdown curve and power duration curves of Batu dam respectively. 


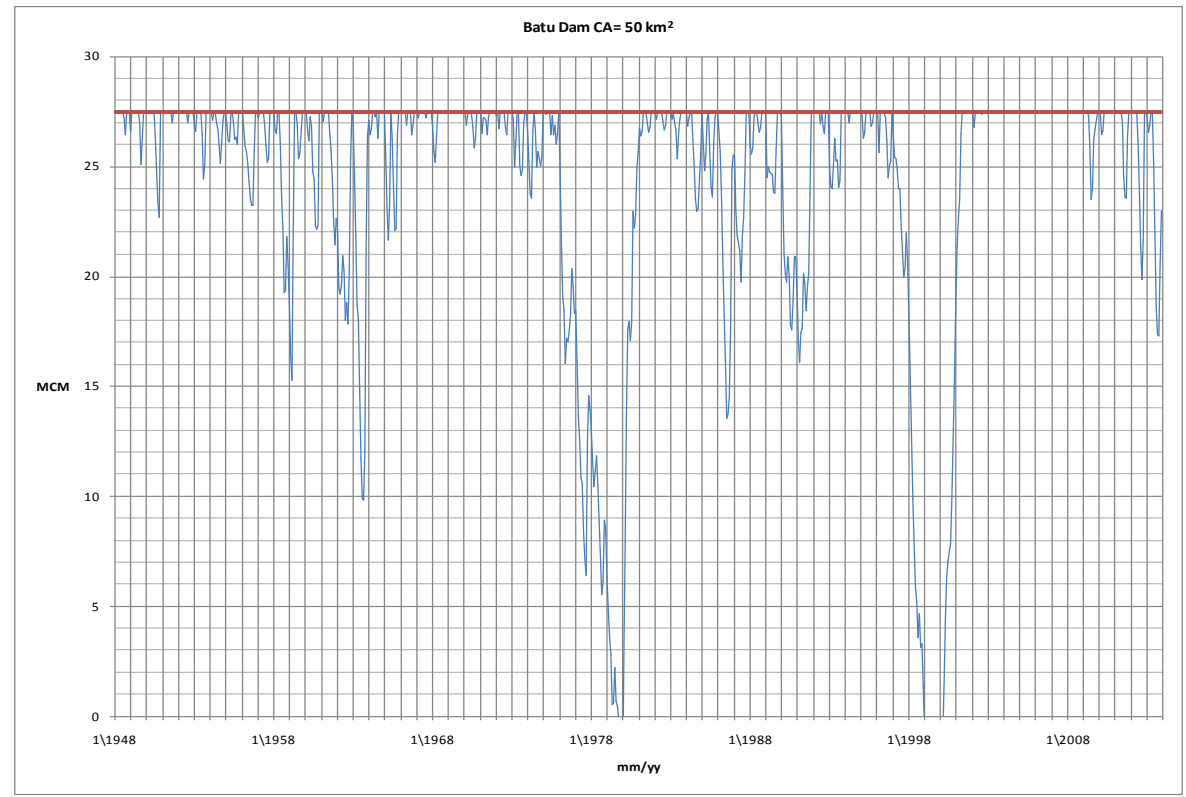

Figure 8: Drawdown Curve for Batu Reservoir

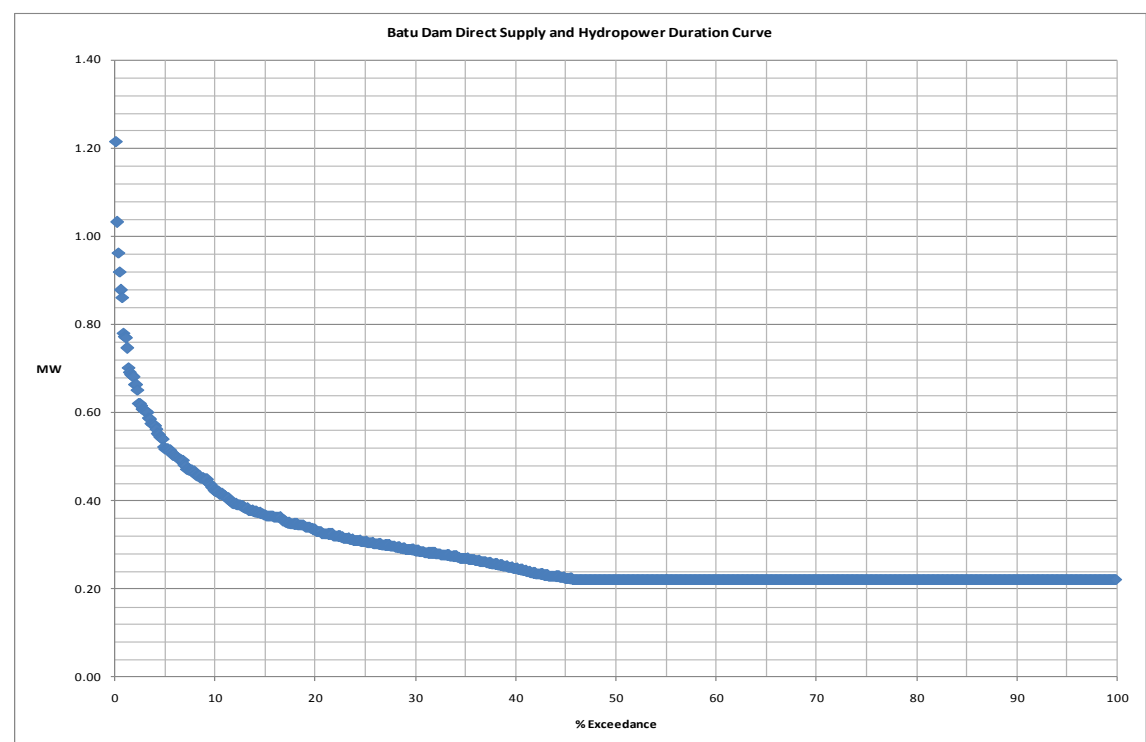

Figure 9: Batu Dam: Power Duration Curve

\subsection{Conclusion}

A hydropower feasibility study for four (4) existing reservoir schemes was carried in an attempt to harness renewable energy by retrofitting 
and changing the mode of operation. Overall, the results showed that only a meager power of less than $1 \mathrm{MW}$ could be harnessed based on $50 \%, 80 \%, 90 \%$ and $95 \%$ probability exceedance for both schemes (see Table 1). This was mainly attributed to the fact that the storage capacity and the elevation differences, both key variables in hydropower generation, were inadequate. In addition, these variables are the most important independent variables in power estimation. Both reservoirs are considered as annual storage type where the refilling on average, takes only about a year with significant runoff generated at the respective dam sites. The average energy output on average varies from 2.4 to $5.68 \mathrm{GWh} /$ year. The Klang Gates dam scheme is the highest if compared to the other three schemes. In addition, the output strongly correlates to the elevation difference in head as the flow rates are about the same order of magnitude. There appears to be limitation for potential hydropower development at the Klang river basin as both Klang Gates and Batu dams are smaller in capacity and lower height.

The reservoir development where conjunctive power generation and raw water supply to the WTPs perhaps were not essential considerations during the earlier detailed design stage. This therefore makes future retrofitting exercise difficult and inherently cost ineffective at the outset. At best, hydropower generated from both proposed reservoir schemes could only meet in-house power consumption. Nevertheless, it is possible that the generated power is connected to the national grid for claims of clean energy development mechanism (CDM) credit as well as Feed-in-Tariff (FiT). One of the renewable energy technology which qualifies for FiT in Malaysia is small hydro. This mechanism allows electricity produced from small hydro facilities to be sold to power utilities at a fixed premium price of RM0.26/kWh for twenty-one years to enable financial viability of small hydro plants developments for installed capacity of up to $2 \mathrm{MW}$ (Seda, 2016).

Compared to large scale hydropower development, both in terms of hydrological and hydraulic adequacy, these smaller existing water supply reservoir schemes may not be of enormous potential commercial value. Nevertheless, it is capable of providing sufficient 
power for local plant consumption and in the vicinity of water treatment premises in the name of energy sustainability, thus paving for a sustainable renewable energy growth trajectory for the energy industry in Malaysia.

\subsection{References}

F. Carrasco, Introduction to Hydropower. The English Press, Delhi, India (2011).

J. Chen, H. Shi, B. Sivakumar, and M. Peart, Population, water, food, energy and dams. Renewable and Sustainable Energy Reviews, 56, 828 (2016)

M. Johnson, DD. Ratnayaka, and MJ. Brandt, Twort's Water Supply, $6^{\text {th }}$ Edition, Butterworth-Heinemann, London, UK (2009)

S. Kucukali, Hydropower potential of municipal water supply dams in Turkey: A case Study in Ulutan Dam. Energy Policy, 38. 6534-6539 (2010)

Lembaga Urusan Air Selangor (LUAS), www.luas.gov.my, (2012)

TN. Manders, J. Höffken, EBA. Vleuten, Small-scale hydropower in the Netherlands: Problems and strategies of system builders. Renewable and Sustainable Energy Reviews, 59, 1493-1503 (2016)

LW. Mays, Water Resources Engineering, Second Edition, John Wiley, NY, NY (2011)

MK. Mishra, N. Khare, and AB. Agrawal, Small hydro power in India: Current status and future perspectives. Renewable and Sustainable Energy Reviews, 51, 101-115 (2015)

S.S.M. Mol, J. M. Kornman, A. J. Kerpershoek and A. W. C. van der Helm, Opportunities for public water utilities in the market of energy from water. Water Science and Technology, 63 (12), 29092915 (2011)

Sustainable Energy Development Authority of Malaysia (SEDA Malaysia), http://www.seda.gov.my/ (2016) 
Suruhanjaya Tenaga (Energy Comission), Peninsular Malaysia electricity supply outlook 2016.

http://www.st.gov.my/index.php/component/k2/item/680-peninsularmalaysia-electricity-supply-industry-outlook-2016-download.html (2016) 